\title{
Variability in echocardiography interpretation
}

\author{
Joseph C. Lee ${ }^{1,2}$ (1) $\cdot$ Alaa Alghamry ${ }^{1}$
}

Received: 30 November 2021 / Revised: 30 November 2021 / Accepted: 15 December 2021 / Published online: 20 January 2022

(c) Japanese Society of Echocardiography 2021

We thank Anderson et al. [1] for vocalising and validating what we have suspected for a while in our clinical areas but been unable to study adequately. There seems to be a significant spectrum of variability in interpretation of echocardiograms. Even though their study was relatively small, it highlighted the problem quite well. Apart from experience, what other factors would they consider to play a role in the observed differences?

In this regard, we strongly advocate for a greater degree of leadership to improve skills from the less expert members of the team [2]. Leadership is a vital element in many other areas of health as well and is a key component of patient safety as well as quality improvement [3-6]. Enhanced education has also been suggested to facilitate this outcome [7]. Beyond improved leadership and education, what else can the authors suggest to improve the consistency of echocardiography interpretation and reduce variability?

By contrast, for example, software for myocardial perfusion scintigraphy (MPS) includes automated analysis of motion [8]. Is automation the way for echocardiography in the future? This idea has also been suggested elsewhere [9, $10]$.

\section{Declarations}

Conflict of interest Joseph Lee and Alaa Alghamry declare they have no conflict of interest.

Human/animal rights This article does not contain any studies with human or animal subjects performed by any of the authors.

Joseph C. Lee

Joseph.Lee@health.qld.gov.au

1 The Prince Charles Hospital, Chermside, Brisbane, QLD, Australia

2 Faculty of Medicine, University of Queensland, Herston, Brisbane, Queensland 4006, Australia

\section{References}

1. Anderson DR, Blissett S, O'Sullivan P, Qasim A. Differences in echocardiography interpretation techniques among trainees and expert readers. J Echocardiogr. 2021;19:222-31.

2. Lee JC, Alghamry A. Leadership to improve consistency in echocardiography data. J Echocardiogr. 2020;18:265-6.

3. Sandberg KC. Leadership in quality improvement. Curr Probl Pediatr Adolesc Health Care. 2018;48:206-10.

4. McKean EL, Snyderman CH. Leadership driving safety and quality. Otolaryngol Clin North Am. 2019;52:11-22.

5. Moffatt-Bruce S, Clark S, DiMaio M, Fann J. Leadership oversight for patient safety programs: an essential element. Ann Thorac Surg. 2018;105:351-6.

6. McFadden KL, Stock GN, Gowen CR 3rd. Leadership, safety climate, and continuous quality improvement: impact on process quality and patient safety. Health Care Manag Rev. 2015;40:24-34.

7. Johri AM, Picard MH, Newell J, et al. Can a teaching intervention reduce interobserver variability in LVEF assessment: a quality control exercise in the echocardiography lab. JACC Cardiovasc Imaging. 2011;4:821-9.

8. Lee JC, West MJ, Khafagi FA. Myocardial perfusion scans. Aust Fam Phys. 2013;42:564-7.

9. Leeson P, Fletcher AJ. Combining artificial intelligence with human insight to automate echocardiography. Circ Cardiovasc Imaging. 2019; 12:e009727.

10. Furiasse N, Thomas JD. Automated algorithmic software in echocardiography: artificial intelligence? J Am Coll Cardiol. 2015;66:1467-9.

Publisher's Note Springer Nature remains neutral with regard to jurisdictional claims in published maps and institutional affiliations. 